of physical training in proper school gymnasiums under proper conditions. There is no dissenting voice among them and we must bend to their opinion. Exercises given in a poorly ventilated room between the desks amount to very little but are good as far as they go. A proper gymnasium is important. They are all agreed as to the effect of one in improved health, better mental work, improved physical development, and several have insisted that such a routine induced better home condition in many pupils. The high schools in Boston without gymnasiums are: 'The Girls' High ( 1,075 pupils) has a hall, the Girls' Latin (357 pupils) has a hall, the Boston Normal (214 pupils) has not even a special room. In these schools are about 1,650 pupils, mostly over thirteen years old, representing about half of the girls attending high schools in Boston without gymnasiums or proper facilities for gymnastic work, except such gain as may be got by free standing work in an empty hall not intended for the purpose. In no one of the grammer schools, containing 40,500 children, the bulk of whom are between nine and fourteen; is there a gymnasium. Two or three have a little apparatus in the corridor.

Whatever the merits of the school curriculum may be, we must pay attention to the opinion of these teachers as to the remedial effect of proper physical exercisc in combating the effects of over. work, if it exists. It seems to be the business of the medical profession to call attention to this, as the general community is not awake to the situation in any sense.

I have not dwelt on the evil effects of examinations, because there was so much to be said on the other question. The teachers are awake to it, and many are minimizing these bad effects. One teacher gives no marks on examinations except passed or failed; the anxiety to attain higher rank than one's neighbor has gone, and the girls have improved. At another school, examinations are arranged so that no girl need take all her examinations during her menstruation. Many of the teachers are awake to the importance of short periods for examinations and long intervals between them. Yet, in a neighboring city, I am told, threehour examinations are still given to grammarschool children.

In short, the health of school girls about puberty seems to be far from what we would like to see it. It seems the result of school work plus outside demands. The school part should be corrective and not an added burden. The development of proper gymnasiums and a sufficient importance given to physical training seems one important part of the remedy.

Vinesa has lost another of its great men. The death of Kaposi was followed by the retirement of Krafft-Ebing after thirty years' incumbency of the chair of psychiatry, etc. His leave-taking was an impressive ceremony. He will make his home henceforth at Graz.-Journal American Medical Association.

\section{STATISTICS REGARDING HEALTH OF SCHOOL GIRLS.1}

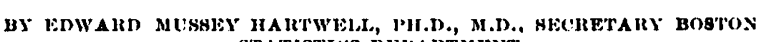
S'TATIBTICB DIIARTMENT.

I was invited to speak on the statistical aspects of the question under discussion, and more particularly with regard to the number of girls who leave school on account of ill health. I must acknowledge at once that so little scientific study has been devoted to the health of the school population in the United States, that statistics relating to the effects of school life that are at once comprehensive and trustworthy are hardly to be found anywhere in this country. For the most part, the subject has been ignored. Broadly speaking, state and local boards of education render no account to the public of the number of school children who are temporarily or permanently incapacitated by disease, or of the number whose names are transferred from the school rolls to the register of deaths. The deaths of school children as such, at least in Massachusetts, are not required to be recorded by anyone.

It is useless, therefore, to attempt to determine accurately even the crude death-rate of Boston school children, not to speak of special death-rates due to particular diseases. An approximate deatlirate may be computed if we assume that the age period, 5 to 15 years, covers what is termed the school age. It must not be forgotten that it is an assumption, since there are some hundreds attending school who are under 5 and several thousands between 15 and 20 years of age; - the school census is taken annually to determine the number of persons in the age period, 5 to 15 . Their number in 1900 was 90,144 , of whom $77 \%$ were in public schools, $16 \%$ in private schools and $7 \%$ not in school. In 1900 there were 483 deaths of persons of the age period, 5 to 15 . By dividing the total deaths of persons of 5 to 15 into three classes proportionate to the number of persons of that age period found in public and private schools and not at school, and then computing the ratio of deaths to the thousand living in each class according to the school census, we find the following approximate death-rates: Pupils in public schools, 6.1 per thousand ; in private schools, 5.5; children not in school, 4.9 ; persons 5 to 15 years of age, (1) including those not in school, 5.4; (2) excluding those not in school, 6.04 per thousand. These approximate death-rates cannot be taken as conclusive, still, they throw a little light upon our question, and suggest that the death. rate of children out of school is slightly lower than that of children in school. They throw no light whatever on the death-rate of persons between 15 and 20 years, which probably includes a relatively large proportion of the girls who suffer from overpressure, if such exists. Sufficient data for computing the approximate deathrate of this class of persons in the city or in the schools cannot be had at present.

1 Read betore the Boston Soclety for Medical Improvement, Dec. 16, 1901 . 
It does not appear that Boston's general and special death-rates compare very favorably with those of other great cities at home or abroad, though our general death-rate is lower than it was. Thus, the mortality per thousand inhalitants of all ages in Boston was 20.8 in 1900, against an average rate of 23.3 in the decade 1881 to 1890 , in which decade Berlin had an average annual death-rate of 24.5 , and London one of 19.1 . In 1892 Joston and the London slums had identically the same death-rate, namely, 23.9 .

'The death-rate for the age period, 5 to 15 , is of special significance, as it is the decade of human life in which children grow fastest and deathrates are lowest. Six year's ago I had occasion to show that Boston's average annual death-rate for the period 1885 to 1890 per thousand among persons from 5 to 15 , namely, 6.6 , was high in comparison with the Borlin rate of 4.8 and the Iondon rate of 3.9 for the same 5 years. How it compares with such rates in London and Berlin today, I cannot say, but we may note with satisfaction that in Boston the death-rate for the year 1900 among persons 5 to 15 years of age, namely, 5.4, was 1.2 per thousand less than the average for the years 1885 to 1890 .

'The death-rates of Boston school girls cornpare quite favorably with those of Boston school boys, as might be expected on general principles; but lack of time forbids my entering into any argument on the question in this connection. It is the fashion to disparage and criticize the public school system here and elsewhere, but those who aver that public school pupils are heavily and dangerously overburdened have not produced convincing evidence that it is so. In my opinion, neither the critics nor the defenders of the schools are in a position to enlighten the public on the matter, for the simple reason that no adequate investigation of the facts has been attempted liitherto.

So far as I can learn, the only states in which thoroughgoing scientific investigations of the effects of school life upon the school population have been made are Sweden and Denmark. The reports of the Swedish and Danish commissions, made more than ten years since, are most instructive, and abound in statistical tables. We have nothing to compare with them, and are not likely to have unless the medical profession shall bestir itself in ways it has not attempted as yet.

I have not been able to ascertain much that is new in reply to the question "How many girls leave the Boston public schools in the course of a year?" Many boys and girls do leave, but the reasons for their leaving (the number reported as going to work being left out of the account) cannot be stated accurately. In the Monthly Bulletin of Statistics, published by my department, there is a table which shows by classes of school, namely, high schools, grammar schools, etc., and by sox the total number of pupils belonging at the end of each month. Another table shows the number of employment certificates given to persons of school age by the school committee from month to month.

The school year begins in September and ends in June. I have made a table showing the number of boys and girls belonging at the end of the several months of the school year, from September, 1899 , to June, 1901, 20 months in all -10 for the year 1899-1900, and 10 for the year 1900-1901. In each year the maximum number of girls in all schools fell in November, the third month, and the least number fell in June, the tenth or last month. The difference between maximum and minimum, which we may term "loss," amounted to $4.8 \%$ of the maximum in the first year, and to $5.1 \%$ in the serond.

As regards all boys, their maximum was reached in November of the first, and October of the second, year, and their minimum fell in June in both years; the loss amounted to $4.9 \%$ of the maximum in the first year and $4.6 \%$ in the second. In the first year the loss among boys and girls was practically the same; in the second year that of girls was slightly greater, namely, one-half of $1 \%$. This does not suggest that girls as a class suffered overmuch.

As to the several classes of schools, the facts may be stated as follows:

(1) Kindergartens: Maximum enrollment in April, minimum in September, in both years, for girls and boys alike; difference between maximum and minimum, or loss, equalled $13.1 \%$ of the maximum in the first, and 13.9 in the second, year, for girls, against $11.9 \%$ the first, and 13.4 the second, year, for boys.

(2) Primary schools: Maximum in January, minimum in September, for girls and boys alike, in the first year ; second year, maximum in January, minimum in September, for girls, and for boys maximum in April, minimum in September; the loss equalled $4.8 \%$ of the maximum in the first, and 3.5 in the second, year, for girls, against $5.4 \%$ in the first, and 3.6 in the second, for boys.

(3) Grammar schools: For girls, maximum in October, minimum in June, first year; maximum in November, minimum in June, second year; for boys, maximum in October, minimum in June, first year; second year, maximum in January, minimum in June; the loss was $5.9 \%$ of the maximum in the first, and 5.7 the second, year, for girls, against 6.7 in the first, and 6.3 in the second, year, for boys.

(4) High and Latin schools: For boys and girls alike in both years the maximum enrollment fell in September and the minimum in June; the difference between the maximum and minimum equalled $20.1 \%$ of the maximum in the first, and 20.9 in the second, for girls, against 20.5 in the first, and 19.8 in the second, for boys.

(5) Normal school: Pupils all females, and mostly young women over 19, the maximum enrollment was in September and minimum in June in both years; the loss amounted to $28.8 \%$ of the maximum in the first, and 42.9 in the second, year. The increase of loss in the second year is explicable on the ground that the requirements for en. 
trance and continuance in the school had been raised.

The proportional losses do not vary widely in the two years under review, and the figures I have given do not justify the supposition that a disproportionate number of girls are obliged to leave the Boston public schools because of impaired health. Excepting the normal sehool, which should be regarded as a technical or professional school, the largest annual losses, in any class of schools, are found in the high and Latin schools. There the losses are considerably larger than in the lower schools. If overpressure exists, they are the schools in which we should expect to find evidences of it.

If any class of public schools need to be investigated with a view to determining the effects of school life upon the health of girls or boys, that class is the class of high schools.

I venture to say that the medical profession is fully as responsible as the educational authorities for the present neglect of school hygiene and the undeveloped state of vital statistics relating to the school population. At the same time, the physi- in cians are somewhat more fully alive than the teachers to the needs of the situation.

\section{THE EFFECT OF PUBLIC SCHOOL EDUCA- TION UPON TIIE IIEALTI OF THE COI- I.EGE GIRI.1}

$$
\text { BV JAND KHLL BAHNE. M.D., HOKTON. }
$$

Tuose who have preceded me in this discussion have pointed out the dangers to the health of growing girls in our public school education.

We are now to consider the effect upon the college girl. She enters with the same neurotic tendencies that she acquired in school life. These may progress to such an extent that they culminate in a breakdown. On careful questioning by the physician it will be found that the foundation of ill health was laid, in the majority of cases, during the age of puberty. Another may, by rigidly conforming to the rules of health, maintain such an equilibrium of her forces, that she leaves the institution in much the same physical condition as when she entered. Still a third, who starts with delieate health, will gain during the added years of study, and go out in to the world a stronger, more robust woman.

$\Lambda$ medical adviser today who makes a physical examination of girls, when they come to college, broadly divides them into two groups - athletic and non-athletic.

It is ten years since Dr. Sargent had modeled a statue representing the typical American student - the $50 \%$ class. Were he to have one made of the same percental grade now, the proportions would have to be changed. The type would be better hecause of the influence of gymnastics and athletics in the lower schools. Bicycling, golf, and increased interest in all out-of-door sports 1 Real before the Boston Society for Medical Improvement Dec. 16, $1 ! 01$. have also done much to raise the standard. Nevertheless, the faults of the American type would still be marked, namely, flat cliest, hollow back and prominent abdomen.

Olservation of 2,000 students in finishing schools and college, gave the following tabulated results: Thirty per cent. were either wearing glasses or ordered to have their eyes examined by a special. ist; $6 \%$ showed defective hearing; $4 \%$ had flatfoot; $5 \%$ had weak lungs; $4 \%$ had heart trouble ; $2 \%$ had kidney lesions. Nenstrual difficulties were the most marked : $75 \%$ were found with irregularities dating from puberty; $60 \%$ had to give up from one-half to two days, and $90 \%$ had leucorrhea. Of those whose records were kipt of four yearly examinations (up to the beginning of the senior year), $30 \%$ showed marked improvement, $30 \%$ were not influenced either way, while $40 \%$ were not improved.

Since these defects date to the time when menstruation first takes place, when habit neuroses are most easily formed, when morbid sensitiveness keeps the girl at work in sohool, the reconstruction in her education must he made in the preparatory schools. For whatever position in life she is to occupy she needs good round health. Education at the expense of health is worthless. A sound mind in a sound body is a priceless possession. The college girl should represent that type.

\section{Elinital פDepartment.}

\section{MASSACIIUSETTS GENERAI IIOSPITAL. CLINICAL MEETING OF THE MEDICAI BOARD.}

Regulali meeting, Dec. 20, 1901, Dr. C. 13 . Porter in the chair.

DR. II. F. VICkinY reported the following case :

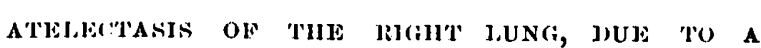
FOREIGN HODY IN THE RIGH'T PRIMARY BRONillus.

$\Lambda$ boy, age six, had a bean in his moutl, when he was knocked down by a companion, and the bean was drawn into the trachea. Ile was admitted on the surgical side, under Dr. Harrington's care, and Dr. Harrington very kindly invited me to examine the boy. I saw him on July 5, the day after the accident. At that time the right chest was decidedly smaller than the left, and the heart drawn over toward the right side; relative dulness existed in the right lung, and respiration was nearly absent. What respiratory sound there was was of a harsh bronchovesicular character. If we had not been sure from the report of Dr. Lord, my chief house officer, that the day before the conditions had been different on that side, it would have seemed possible that the lung was in a chronic state of collapse. I agreed with Dr. Harrington as to the advisability of trying to get the bean from the right primary 